https://doi.org/10.48009/2_iis_2010_48-53

\title{
INCREASING MIS ENROLLMENTS IN THE INTRODUCTORY COURSE: TEACHING STUDENTS TO DEFINE MIS BY DOING IT
}

\author{
Raymond Frost, Ohio University, frostR@ohio.edu
}

Sarah Pels, Ohio University, sarah.pels@ gmail.com

\begin{abstract}
This paper describes a redesign of the Introductory MIS course to more accurately reflect the systems analysis and design focus of the MIS major. The redesign also packages the course so as to help recruit students into the major. These seemingly incompatible goals are both achieved by engaging and challenging students with interesting projects and concepts. The redesign is developed citing evidence from the literature and based on conversations with IS colleagues and industry professionals.
\end{abstract}

Keywords: Introductory MIS Course, Curriculum Design

\section{INTRODUCTION}

An introductory Management Information Systems (MIS) course should accomplish three goals: introduce IS fundamentals, develop software skills, and recruit students into the major. Of these three goals, the most elusive is recruiting students as evidenced by the national decline in IS enrollments. In order to simultaneously achieve all three goals, the course must engage and interest students. Once students experience a high level of self-efficacy and interest, they will be inclined to choose MIS as a major [1].

Students in an introductory MIS course often ask what a career in MIS looks like. Lacking a clear vision, students make their own assumptions. Often they assume the career involves programming with little human interaction. The idea that MIS is a solely technical field could not be further from the truth. MIS job descriptions typically require candidates to be able to collaborate, communicate, analyze needs and gather requirements. They also list the need for excellent written and communication skills [13]. In other words, MIS workers are constantly interacting with other people both inside and outside the organization. They are coming up with creative solutions to business problems through analysis and critical thinking [13].
The introductory course is typically the first and strongest impression that students have of the MIS major [5,10]. Many students have never heard of MIS before coming to college. And to quote an old adage, one never gets a second chance to make a first impression. Rather than give students a high-level look at the field, the redesigned course helps students get a feel for what a career in MIS would be like by doing MIS.

\section{COURSE BACKGROUND}

The course described here is an introductory management information systems course taught at a large Midwestern university both in-class and online. Sixty percent of the students come from within the College of Business, while remaining students come from other colleges at the university. Eighty percent of the students are freshmen or sophomores. The course is offered both in-class and online. The in-class course mixes a large lecture with break out lab sections. Online sections are smaller in size. The lecture component of the online section is a video capture of action on the instructor's screen with recorded voice over.

The software used in the course includes Microsoft Word, Excel, PowerPoint, and Google Sites. The theory taught in the course includes the systems development life cycle, business process analysis, interface design, market segmentation, budgeting, forecasting, schematic reports, and presentations. Overlaying all the deliverables is a strong emphasis on professionalism and graphic design.

\section{SYSTEMS ANALYSIS AND DESIGN}

The core of every MIS curriculum is the course in Systems Analysis and Design-typically a junior level course. Arguably this is the first time that students experience what the career looks like. However, by this time they have already chosen a major, so the course cannot serve as a recruitment vehicle.

The authors' goal is to create a systems analysis and design project in the introductory course- 
albeit at a lower level. The entire course is built around a single project - the design and marketing of a unique iPhone application to solve a business problem. Each student must identify a business problem and how his or her app solves the problem. This is a very creative exercise and the instructors have been amazed at some of the proposed apps.

To emphasize MIS content, students follow the first three stages of the Systems Development Life Cycle (SDLC):

Current state analysis. Students provide a written analysis of the problem. Using a Unified Modeling Language (UML) diagram with actors in swim lanes, the students create an As-is process flow. The UML diagram is created in PowerPoint using basic drawing tools.

Requirements definition. Students create a UML diagram to depict the To-be process flow. Students also design the user experience (UX). They identify three market segments that might use the app, then target one of those market segments. Students develop a fictional persona who will use the app. All interface design specifications must reference the persona.

Design. Using a freely available PowerPoint template called MockApp, students create a realistic mockup of the app. The interface elements in MockApp look identical to an actual iPhone screen. Students create multiple screens for their app - each as a separate PowerPoint slide. They can even activate buttons using PowerPoint's hyperlink feature. This allows students to create a realistic walkthrough of the app.

Note to this point in the course students have not created a single bulleted slide in PowerPoint. Rather PowerPoint is introduced as a drawing tool. Furthermore, adherence to graphic design principles - contrast, repetition, alignment, and proximity is also required in the deliverables.

Next students create a website using Google Sites to market the application. The website features screen shots from their iPhone app as well as company and positioning information. Students must adhere to graphic design and usability principles in construction of the website.

Next students budget development of the application using Excel. They calculate and graph contribution margin and the breakeven point. Students also forecast sales growth using historic data on iPhone sales.

Finally students prepare a schematic report, similar to that prepared by a consultant, to sell their business plan to an angel investor. The schematic report utilizes PowerPoint as a page layout program to integrate text and graphics in a visually appealing fashion. Students also prepare a presentation to accompany the schematic report. These presentations are created using a online presentation tool called Prezi. If the metaphor for PowerPoint is a deck of slides, the metaphor for Prezi is a large white board. Students pan and zoom in on different portions of the Prezi as they navigate through their presentation.

In sum, over the course of the semester, students plan, design, and market an iPhone application. They analyze the current state, elicit requirements, design the app, and build a website prototype to help market and support the app.

Students are engaged because the project is fun. However, they are simultaneously learning business concepts and MIS skills. Now, even as freshmen, students have a real experience of MIS in operation.

A by product of creating an engaging course is increased enrollment in the MIS major [1]. Even students who have never heard of MIS become excited about the major and either switch majors or add it as a double major.

\section{REALIGNING INSTRUCTIONAL GOALS}

This course has been in constant revision over the last seven years in an attempt to satisfy the goals of both the College of Business and the MIS department. Earlier versions of the course erred on the side of serving as a support course with a recruiting focus rather than emphasizing the MIS material $[8,9,14]$. The course drew students to the MIS major thereby serving a recruiting goal, but left them feeling somewhat misled as to what the major is all about.

Prior to the most recent redesign, the course was designed to support skills development while ignoring MIS content. The course lacked a focus on IS fundamentals. Currently, the course has realigned itself with the goals of the MIS department by using software tools to solve MIS problems. Nonetheless the exercises are 
carefully designed so that students can generalize skills to business problems in other disciplines.

The current version simultaneously accomplishes all three goals - introduction to IS fundamentals, software skills development, and recruitment into the major. The achievement of these goals was not a coincidence. The goals have been at the forefront of the design of the course and are the result of intentional actions taken to accomplish them.

There are many ways to engage students in virtually meaningless ways or to interest students by superficial means. But instilling an honest and genuine attraction to the field is a more difficult task that requires careful design.

The following section will describe the various ways in which the course was designed. In turn, the structure of the course has led to the successful achievement of instructional goals through genuine student engagement and interest.

\section{METHOD AND DISCUSSION}

The claim of a strong design focus has many applications for the purpose of this course. Design is used in a variety of contexts. Five specific usages of the word will be described as each pertains to the development of the course. See Figure 1 below.

\section{STRONG DESIGN FOCUS}

To begin the discussion of design and its many applications to this course, it might be helpful to establish a fundamental definition of design that applies to each of the five cases in a meaningful way. The working definition will be that design is the intentional action that results from discovery and analysis. This course developed through an iterative process of intentional actions - creation, trial, feedback, modification, and so forth.

\section{PEDAGOGICAL DESIGN TO DEVELOP SELF-EFFICACY}

Pedagogical design is one of the main influences on the development of the course in achieving the three primary goals laid out in the last section. The structure of this course recognizes the fact that practicing a range of innovative pedagogical techniques has a strong relationship with student interest [1].

Volume XI, No. 2, 2010
One pedagogical goal is for the course to support and model critical thinking. One of the ways critical thinking is promoted is by the use of innovative instructional techniques that are explained elsewhere [10]. This use of instrumental assistance is critical in promoting student interest and individual growth in the skills and concepts [2].

The course incorporates a variety of teaching styles both in and outside of the classroom including videos, demonstrations, lecture, handson lab time, textual support, nearly wordless diagrams, in-class discussions, and challenging assignments and activities. Through the use of nearly wordless diagrams, videos and textual support, students have a number of resources available to them to complete assignments.

Assignments for this course are designed to achieve increasing complexity in two ways. The first is through progression through the SDLC stages as applied to on-going iPhone app project. As students become more comfortable with their skills and understanding of concepts, they experience more confidence in completing more difficult tasks [1]. Consequently, the assignment structure of this course is an on-going project that slowly gains intensity from week to week. The second way is through a progression of difficulty within each week's group of tasks. Each assignment is labeled Level 1, Level 2, or Level 3 (L1, L2, or L3) depending on the complexity of the task. The quality of a course's pedagogical design establishes a crucial foundation for the effective delivery and reception of the content of the course.

As a result of this pedagogical design, enduring learning takes place and builds students' selfefficacy. Research has shown that there is a significant relationship between perceived selfefficacy and the development of educational and vocational interests [2]. Research also points to the fact that students have a tendency to develop enduring interests in areas in which they view themselves as proficient [4].

\section{DESIGNING THE COURSE TO HELP MARKET THE MAJOR}

There are several ways in which the design of the course plays a key role in engaging students and recruiting them to the major. By picking a trendy and innovative subject, students experience a high level of interest [1], which encourages them to produce higher-quality
Issues in Information Systems 
deliverables. Students design and make the business case for a new app for the iPhone. Assignments are developed to emphasize the visual and creative aspects of the deliverables, topics to which students naturally gravitate. The visual and creative elements of the tasks result in more professional deliverables. That coupled with the progressive nature of the project gives students a positive feel for a career in the MIS field.

\section{PROCESS DESIGN THROUGH THE SDLC}

The emphasis on process design leads the course to have a focus on the Systems Development Life Cycle (SDLC). This is a concept that is typically not introduced until a mid to upper level MIS course. However, it is logical to connect this core way of design thinking and problem solving with a student's first impression of the major. Students experience the process of designing a solution for a business problem through the steps of the SDLC.

More specifically within the SDLC, the course concentrates on the analysis, requirements, and design phases. Students spend significant time on the creative aspects of the project, which leads to an engaged and interested group of students. Students are asked to be intentional about their design choices, relating them back to the requirements that they uncovered earlier in the project. With a strong emphasis on the SDLC, the course achieves a focus on IS fundamentals. The course creates countless opportunities for discussions on a number of IS issues and concepts in the context of the iPhone app project. Students build interest in IS and are more likely to pursue the major [1].

\section{ANALYTICAL DESIGN INFLUENCES STUDENT LEARNING}

Analytical design helps achieve the goal of teaching IS fundamentals while simultaneously engaging students. The influence of analytical design is due to the work of Edward Tufte, perhaps the world's leading expert on the design and display of quantitative information. Tufte insists that the focus must first be on the quality, relevance, and integrity of content. He has an especially sensitive eye for the ethical dimension-telling the truth in a visual information display. High quality content is followed by its representation in an effective design to communicate that content [15].
This course directly incorporates three of Tufte's six information design principles: show comparisons, show multivariate data and produce proper documentation. Students create graphics that show comparisons among multivariate data and document their work by citing credible sources and displaying authorship. By learning techniques to effectively display information, students gain valuable skills in creating and analyzing information graphics which they can employ outside of the course [16].

\section{GRAPHIC DESIGN ENCOURAGES CONFIDENCE AND PROFESSIONALISM}

The final influence of design that is carried throughout the course is graphic design. Four principles of design are introduced on the first day of class: contrast, repetition, alignment, and proximity. Throughout the entire course, students are expected to apply these graphic design principles to all tasks. These principles are looked for in all assignments that are submitted including their iPhone app, website, presentations, spreadsheets, graphical representations, and so forth.

Students report an appreciation for the value of these principles and begin to train their eyes to recognize good design. They are inspired by their ability to produce professional deliverables. Students develop a sense of pride about their accomplishments and enjoy the personal growth experienced throughout the course.

\section{CONCLUSION}

Careful design from a variety of perspectives is necessary to achieve all of the goals that the course is required to meet. In prior versions of the course, one or more of the design elements has been absent, and the goals of the course suffered. Students will take more away from the course when they are personally invested in the subject. In order to attain that investment, the course must be delivered in way that encourages learning in an exciting and engaging environment. Once students become invested in the course, enrollments into the major will increase. We have taken a number of other measures to increase enrollments including hosting business panels and networking events, consistency in our curriculum, and a strong student focus. Our enrollments have increased $400 \%$ over seven years. While it is difficult to assign a portion of this increase to the 
introductory course, nonetheless, we hear from many students that they would not enter the major without a positive experience in the introductory course.

Through the implementation of this course redesign, it is now possible for students to explore IS fundamental concepts, develop software skills, and build a lasting interest in the MIS major all through an introductory level course.

\section{REFERENCES}

1. Akbulut, A. Y., \& Looney, C. A. (2007). Inspiring Students to Pursue Computing Degrees. Communications of the ACM, 6771.

2. Akbulut, A. Y., Looney, C. A., \& Motwani, J. (2008). Combating the Decline in Information Systems Majors: The Role of Instrumental Assistance. Journal of Computer Information Systems, 84-93.

3. Akbulut, A. Y., \& Looney, C. A. (2009). Improving IS Student Enrollments: Understanding the Effects of IT Sophistication in Introductory IS Courses. Journal of Information Technology Education, 87-100.

4. Bandura, A., \& Shunk, D. H. (1981). Cultivating competence, self-efficacy and intrinsic interest through proximal selfmotivation. Journal of Personality and Social Psychology, 41, 586-598.

5. Elder, K. L., Huber, M., Piercy, C., \& Salisbury, W. D. (2003). The AMCIX 2003 Panel on IS Education-I Let Us Not Throw Out the Baby with the Bath Water: Information, Systems, and Technology All Matter in the Core IS Course. Communications of the Association for Information Systems.

6. Elder, L., \& Paul, R. (2002). Critical Thinking: Tools for Taking Charge of Your Professional \& Personal Life. Prentice Hall.

7. Firth, D., Lawrence, C., \& Looney, C. A. (2008). Addressing the IS Enrollment Crisis: A 12-Step Program to Bring about Change through Introductory IS Course . Communications of the Association for Information Systems, 17-36.

8. Frost, R., Krewatch, L., \& Pike, J. (2008). Generating Student Interest in the Information Systems Major: A Strategic Framework for the Introductory Course. Issues in Information Systems, 188-195.

9. Frost, R., \& Pike, J. (2004). A Revolutionary Approach to the Introductory MIS Course: Professional, Project Based, Decision Focused, Visual and Engaging. Issues in Information Systems, 454-460.

10. Frost, R., \& Pels, S. (2010). Nearly Wordless Techniques for Software Instruction: Increasing Comprehension and Higher Level Learning. Issues in Information Systems.

11. George, J. F., Valacich, J. F., \& Valor, J. (2005). Does Information Systems Still Matter? Communications of the Association, 219-232.

12. Hiltz, S. R., Nardi, B., Rennecker, J., Schultze, U., \& Stucky, S. (2008). Using Synthetic Worlds for Work and Learning. Communications of the Association of Information Systems, 352-370.

13. Kaiser, K., Nunamaker, J. F., Sipior, J. C., Topi, H., Valacich, J. S., Wright, R. T., et al. (2008). Revising Undergraduate IS Model Curriculum: New Outcome Expectations. Communications of the Association of Computer Information Systems, 591-602.

14. McGann, S. (2006). Meeting dynamic IS market demands: Leveraging consulting practices to guide curriculum reform. Issues is Information Systems, 210-215.

15. Tufte, E. R. (1983). The Visual Display of Quantitative Information. Chesire, CT: Graphics Press.

16. Tufte, E. R. (2006). Beautiful Evidence. Chesire, CT: Graphics Press. 


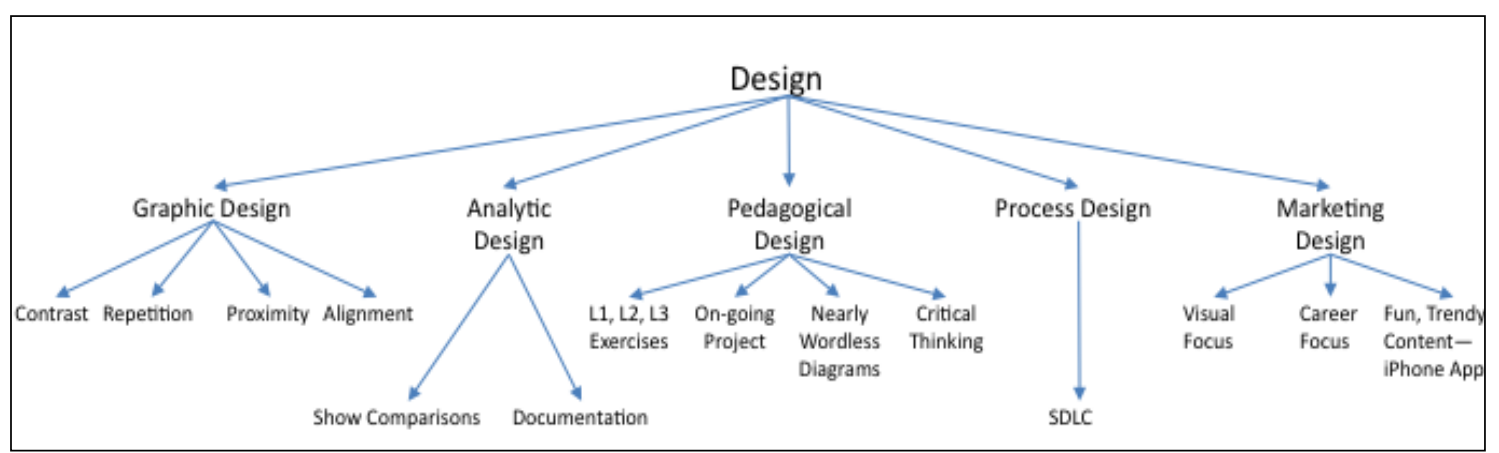

Figure 1: Five Separate Types of Design Applied to the Course 